\title{
La maldición de las redes fantasma
}

\author{
Pedro Chávez Gómez ${ }^{1}$ \\ Cuitláhuac Fernández Uribe ${ }^{2}$
}

Me llamo Tomás Rodríguez, mis amigos me dicen Tommy, tengo 13 años, nací y crecí en el puerto de Mazatlán, los primeros recuerdos que tengo de mi vida son en la playa construyendo castillos de arena y buscando conchitas entre la espuma de las olas. El mar y yo tenemos un vínculo enorme, recuerdo incontables albas y puestas de sol que contemplé desde el malecón, la exquisita gama de sabores de los alimentos que me brindan los mariscos, la relajación que siento con los granitos de arena en mi espalda mientras me tuestan la piel los rayos del sol y esa mística sensación de ingravidez cuando realicé buceo libre por primera vez observando paisajes que parecen de otro planeta.

Hoy tuve un día muy peculiar, mientras dormía tuve una pesadilla donde llovió tanto que toda la ciudad se inundó, al despertar noté que la única inundación ocurrió en mi cama, oriné los dos litros de horchata que bebí ayer durante la cena, fueron necesarios para acompañar la hamburguesa de marlin; ${ }^{3}$ por lavar las sábanas demoré bastante y perdí el autobús escolar, sentí pánico al pensar en regresar a casa para recibir los regaños de mamá, por lo que decidí visitar mi playa favorita Olas Altas, ubicada en el centro del puerto del Viejo Mazatlán, allí observé a los surfistas durante unos minutos y entre las rocas se encontraba un pescador, en ese instante pensé en mi padre, llevaba meses sin saber de él.

Aprendí a nadar gracias a mi papá Diego Rodríguez, él nació en La Paz y es el capitán de un barco camaronero, recorre todo el Golfo de California en busca del preciado crustáceo, sus técnicas de pesca son las más devastadoras en el océano, arrasan con todos los seres vivos del fondo a su paso. Sé que para la naturaleza su trabajo es horripilante, pero la tripulación y los comerciantes que venden mariscos lo consideran un héroe, un exitoso empresario, yo también lo creo, sus esfuerzos pagan mis estudios en un buen colegio y viajamos a otros países durante las vacaciones.

1 Estudiante de la Licenciatura en Gestión y Economía Ambiental del cuCEA. Premio INCIDE Zapopan, 2020. Correo electrónico: pechago90@gmail.com

2 Estudiante de la Licenciatura en Gestión y Economía Ambiental del cucEA.

3 Istiompax indica (Cuvier, 1832). 
Mi mamá también lo extraña a pesar de sus discusiones con él sobre el daño ecológico de su trabajo, son un excelente equipo, ella se llama Hillary Welling, nació en Portland y sus importantes estudios científicos sobre los efectos en los ecosistemas marinos por el cambio climático la trajeron a México. Ella quiere que papá cambie de trabajo porque sabe que esa técnica de pesca tiene un gran impacto negativo en la vida marina, por cada $\mathrm{kg}$ de camarón ${ }^{4}$ pescan $10 \mathrm{~kg}$ de especies no comerciales como las macroalgas, esponjas, hidrozoarios, moluscos, coral y muchas más que regresan al agua heridas o muertas.

Al llegar a casa pensé mucho en ese pescador que miré en el malecón, pasó horas entre las piedras lanzando una tarraya, en uno de sus lanzamientos batalló por sacar su red, trató de liberarla durante una hora sin obtener éxito y se retiró gritando maldiciones a todo pulmón. Ver a alguien con tanto tesón por recuperar su red fue inspirador e intrigante, por lo que pregunté a mamá:

- iLas redes de pesca son costosas?

-Depende del tamaño de la red, las de uso industrial que usan los barcos camaroneros son mucho más caras que las que usan los pescadores artesanales.

- ¿Cuánto cuesta una pequeña de pesca artesanal?

- No cuestan tanto cariño, el material para una red de ese tamaño puede costar 400 pesos, más un día de tiempo que le tomará tejerla, y si valoramos la cantidad de peces que puede atrapar un pescador artesanal, recuperará su inversión en dos días de trabajo duro aproximadamente. Ahora que lo pienso sí es muy costosa para él -me respondió ella.

Con razón el pescador se esforzó tanto por recuperarla, pensé, y continué con mi interrogatorio:

—Cuando los pescadores pierden sus redes en el mar, ¿qué pasa con ellas, se van a las profundidades?

- Si esa red queda atrapada entre las rocas o el coral, se convertirá en una red fantasma, se le llama así porque el nylon con el que las hacen es transparente, muchos animales marinos no la detectan, quedando atrapados sin poder alimentarse y mueren.

-Ahora entiendo por qué tienen ese nombre tan aterrador las "redes fantasma".

-Lamentablemente eso es sólo el comienzo, existe algo más espeluznante, actualmente las redes de pesca se tejen con materiales plásticos que tardan cientos de años en degradarse, durante ese periodo de tiempo se desprenden pequeños trozos de la red, conocidos como microplásticos, que se mantienen suspendidos en el agua y los animales los ingieren, este material no lo pueden asimilar ni desechar, se bioacumula en sus tejidos y puede almacenar grandes cantidades que provocan enfermedades o la muerte.

- ¿Quieres decir que cuando nos alimentamos de pescado estamos consumiendo plástico?

$4 \quad$ Penaeus vannamei (Boone, 1931). 
-Sí, no podemos verlo a simple vista, pero ahí está. Algunas partículas plásticas pueden causar cáncer en los humanos, son sustancias tóxicas.

-i¿Por qué seguimos comiendo esos animales si son tan peligrosos?!

-Es difícil explicarlo, para muchas personas los alimentos marinos son su principal fuente de proteínas, es más complejo de lo que crees cambiar nuestras costumbres; tú tranquilo, todo estará bien cariño, ahora descansa.

Mi madre me arropó, apagó la luz del cuarto y salió; antes de dormir arrullado por el sonido de la lluvia en mi ventana, recordé la vez que acompañé a papá a su trabajo durante mis vacaciones de verano, él estaba en la proa mirando a siete vaquitas marinas ${ }^{5}$ que nadaban entre las olas que creaba el movimiento de la embarcación, fue un evento memorable porque probablemente ese grupo sea la mitad de la población actual, en uno o dos años más se extinguirán.

Una enorme red brotaba levantada por la grúa, se expandió dentro del barco y un enorme calamar ${ }^{6}$ se lanzó al rostro de mi padre, luchó por quitárselo mientras él gritaba a los tripulantes por ayuda, después de unos minutos de forcejeo lograron despegar sus ventosas y uno de ellos preguntó:

-Capitán, iquiere que lo cocinemos al ajillo?

-No, devuélvanlo por la borda, esto es una lección para mi hijo, tiene que aprender a pescar, no a ser pescado.

Cuando estaba por dormir un diluvio se desató, los relámpagos iluminaron el cielo, comencé a pensar en cómo se sacudía tan estrepitosamente el barco que dirige mi padre, el "Evelyn 1", sabía que estaba navegando en el Mar de Cortés lanzando redes junto a su tripulación desde la tarde, él siempre quería capturar la mayor cantidad de toneladas para poder regresar al puerto y venderlas en el mercado, nada se lo impedía, ni los ciclones ni los huracanes, es un hombre de mar.

-iLos mares no descansan y nosotros tampoco! —vociferó el capitán desde el timón a los seis hombres que integraban su tripulación.

- Ya lo oyeron, a trabajar - comentó el primer oficial.

—iiiSíííííi!!!. — gritaron al unísono los demás.

Continuaron durante varias horas más hasta que la llovizna cesó, estaban por lanzar la última red camino al puerto.

- Muy bien chicos, suelten la última —expresó el capitán.

Lo hicieron, cada uno de los seis hombres tomó su posición mientras esperaban que la red trabajara.

De pronto uno de los hombres que guardaba las cajas de camarón vio cómo la última red que habían puesto brotaba hacia la superficie.

—iiCapitán Diego, todos, vengan a ver esto!! —exclamó sorprendido el sujeto.

Los otros cinco caminaron a su lado y no podían creer lo que veían.

—iPor qué tanto alboroto? — preguntó el capitán al salir de la timonera.

5 Phocoena sinus (Norris y McFarland, 1958).

6 Architeuthis sanctipauli (Vélain, 1877). 
$\mathrm{Al}$ acercarse comprendió la sorpresa de los chicos, una ballena jorobada ${ }^{7}$ había elevado la red con su cola, provocando que las cuerdas se rompieran; el evento los paralizó al instante porque recordaron a la ballena blanca de Moby Dick de la historia de Herman Melville.

—iPreparen los arpones! —coordinó el capitán.

La tripulación miraba atenta el horizonte esperando disparar al gigante mamífero, pero pronto el miedo les inundó más al observar unas aletas de tiburón, ${ }^{8}$ cuatro para ser exactos y estaban a punto de chocar con el barco.

—iDisparen! —ordenó mi padre.

Los abatieron de inmediato; para su sorpresa, del otro costado venían dos orcas ${ }^{9}$ enormes que chocaron con el barco, dio la vuelta por completo, los hombres abismaron en la fría y oscura columna de agua.

Al siguiente día los noticieros divulgaron que el "Evelyn 1" se hundió, seis tripulantes se encontraban desaparecidos y sólo el capitán había sido rescatado por un barco de la Marina, que se dirigía a tierra firme para atenderlo de urgencias en un hospital.

Escuchar la narración del reportero me aterrorizó, corrí al puerto para estar con papá en su regreso; mientras esperaba vi a un par de chicos que practicaban apnea, después de varias inmersiones encontraron una red inmensa atorada en el fondo rocoso, había sido abandonada hace tiempo, la red cubría parte de un arrecife coralino, el cual no se veía sano, en su mayoría sufría de blanqueamiento por el impacto que causó la red, esto me lo había explicado mi madre. Mientras ellos admiraban el paisaje submarino, una sombra se proyectó detrás de ellos, los chicos se voltearon y vieron que era una raya ${ }^{10}$ durante algunos minutos admiraron su nado hipnotizante y la forma de su puntiagudo aguijón, la raya se hundió en las profundidades y la perdieron de vista; unos segundos después voltearon de nuevo, la raya se desplazó a gran velocidad hacia uno de ellos, el aguijón del animal atravesó su yugular, perdió la vida en unos cuantos segundos. Su compañero entró en pánico, comenzó a nadar hacia la orilla a toda velocidad, pero su destreza acuática no se compara con la de la raya, rápidamente lo alcanzó y le provocó heridas en los brazos, las piernas y en el abdomen con su aguijón perfectamente diseñado: entraba como cuchillo en la mantequilla por su punta sumamente afilada, y al salir desgarró el tejido con sus orillas aserradas; el chico logró salir del agua, dio algunos pasos en la arena y murió desangrado.

—iTommy! ¿Qué haces aquí solo? Estoy preocupada buscándote por todos lados —mencionó mi mamá.

-Esperaré a papá.

-Él ya está en el hospital, vámonos.

En el camino, mientras ella conducía se soltó en llanto y me comentó:

7 Megaptera novaeangliae (Borowski, 1781).

8 Carcharodon Carcharias (Linnaeus, 1758).

9 Orcinus orca (Linnaeus, 1758).

10 Dasyatis americana (Hildebrand y Schroeder, 1928). 
- Ayer por la mañana me encontraba en el laboratorio analizando muestras de tejido muscular en los atunes ${ }^{11}$ de la bahía, observando el microscopio descubrí algo horrible: los químicos de los microplásticos estaban causando una mutación genética, ilos animales se estaban convirtiendo en una especie de muertos vivientes!

Nos dirigimos a toda velocidad al sitio donde estaban atendiendo a mi papá, el hospital estaba lleno de pacientes que habían sido atacados por todo tipo de bestias, esto era el principio del Apocalipsis en las zonas costeras. Llegamos al área de urgencias preguntando por él; la enfermera llamó al médico que llevaba su caso y explicó:

- Lo siento mucho, hicimos todo lo posible, lamento informarles que el capitán Diego falleció.

En ese momento desperté. iFue otra pesadilla!, pero esta vez sólo me empapé de sudor, el sueño había sido tan real, bajé a desayunar con mi madre y le conté todo. Me escuchó atenta y me respondió:

- Tu maestra me llamó, ya sé que no fuiste a la escuela por ir a la playa, te estás obsesionando con el mar y la pesca, por eso tienes tantas pesadillas. Eres un niño, debes concentrarte en tus deberes.

- Lo siento, todo parecía muy real.

-Ya sé que sucedió, es una premonición o quizá fueron las dos bolsas de suaves que te comiste ayer, ya no te compraré más dulces, prepárate para ir a la escuela dijo sarcásticamente.

Durante mis clases no podía prestar atención, me invadió una sensación extraña, seguía pensando en la pesadilla que tuve. Al terminar mi día de clases tomé un atajo hacia la playa, quería asegurarme que todo estuviera bien; al llegar me repetí a mí mismo:

- Sólo fue un sueño, sólo fue un sueño, sólo fue un sueño, sólo fue un...

La bahía se encontraba llena de cadáveres, hombres, mujeres, niños, algunas personas heridas; el litoral se tiñó de rojo, aún había gente sufriendo ataques por todo tipo de especies marinas, era como una venganza, como una maldición.

Corrí de regreso a casa a toda velocidad, entré por la puerta trasera del jardín y a lo lejos percibí una silueta extraña que atrapó mi atención de inmediato, parecía una sirena varada a la orilla de la piscina; al acercarme me di cuenta de que era un cocodrilo $^{12}$ devorándose las piernas de mi madre hasta la cintura.

—iiMamá, mamá!! — grité mientras corría a auxiliarla.

Ella gritó con un sonido demoniaco, sus ojos eran de color violeta y las venas de su rostro se marcaban demasiado; con sus manos tomó del hocico al lagarto y con una fuerza sobrenatural le arrancó la mandíbula.

Me quedé petrificado con esa escena, los microplásticos que ingirió le hicieron efecto.

—iReacciona, soy yo, tu hijo! iNo! ¿Qué haces? iiSuéltame!!

11 Thunnus thynnus (Linnaeus, 1758).

12 Crocodylus acutus (Cuvier, 1807). 
...Un apocalipsis de animales marinos zombis es sólo ciencia ficción; sin embargo, la realidad es más terrorífica que esta historia. Hasta el año 2017 se introdujeron 6,557 millones de toneladas de plástico al océano, incluidas las redes fantasma que suman a la estadística una tonelada cada 40 segundos, lo que ha contribuido a enormes daños a los ecosistemas marinos y la industria marítima. Por otro lado, el consumo de microplásticos afecta también la salud de la población humana, ya que liberan sustancias tóxicas que alteran los procesos fisiológicos. Es urgente que modifiquemos nuestros hábitos de producción y consumo de materiales plásticos.

\section{Referencias bibliográficas}

Alverson, D. L., Freeberg, M. H., Murawski, S. A., y Pope, J. G. (1994). A global assessment of fisheries by-catch and discards. FAO Fisheries Technical Paper No. 339. http://www.fao.org/3/t4890e/T4890E00.htm

Elías, R. (2015). Mar de plástico: Una revisión del plástico en el mar. Rev. Invest. Desarr. Pesq., núm. 27, pp. 83-105. https://www.oceandocs.org/bitstream/handle/1834/10964/revinidep27_83.pdf

Flanders Marine Institute. (2020). World Register of Marine Species. http://www.marinespecies.org/aphia.php? $\mathrm{p}=$ taxdetails \&id $=712905$

López-Martínez, J., y Morales-Bojórquez, E. (2012). Efectos de la pesca de arrastre en el Golfo de California. Centro de Investigaciones Biológicas del Noroeste, S. C./ Fundación Produce Sonora. https://cibnor.repositorioinstitucional.mx/jspui/bitstream/1001/1242/1/Efectos_de_la_Pesca_Cap\%C3\%ADtulo\%203.pdf

Melville, H. (1851). Moby Dick. Richard Bentley.

Pereiras-Varela, M. (2019). Contaminación marina por plásticos. Tesis de pregrado. Universidade Da Coruña/RUC-UDC. https://ruc.udc.es/dspace/bitstream/handle/2183/24187/pereirasvarela_manuel_tfg-2019.pdf.pdf?sequence $=2 \&$ isallowe$\mathrm{d}=\mathrm{y}$

World Animal Protection. (2019). Fantasmas bajo las olas. (2ª edición). https://sectormaritimo.es/wp-content/uploads/2019/03/Fantasmas-Bajo-Las-Olas-compressed. pdf 